\title{
FILOZOFIJA MUZIKE IZMEĐU OSEĆANJA I FORME ***
}

\section{Suzan Langer o muzici u novom ključu}

Rad je posvećen analizi filozofskog razmatranja muzike Suzan Langer. Predmet ispitivanja je način na koji se Langerova postavlja spram pitanja odnosa muzičke forme i osećanja. Interpretativni ključ predstavlja jezički okret unutar kog Langerova dela, te postavljanje problema u horizont razmatranja uslova mogućnosti izvođenja jedne filozofije muzike. Rezultat istraživanja pokazuje da Langerova prisvaja i preoblikuje tradicionalna određenja muzike u smeru određenja filozofije muzike.

Ključne reči: Suzan Langer, muzika, filozofija muzike, forma, osećanje.

Filozofija muzike jedna je od prvih disciplina koje su unutar estetike - ili, preciznije, unutar filozofije umetnosti - oformljene u cilju filozofskog istraživanja i analize neke konkretne umetnosti. Istorija i tradicija estetike, naime, pitanjima umetnosti mahom pristupa načelno, podrazumevajući jednu suštinu i zajednički pojam za različite manifestacije fenomena umetničkog, bilo da je reč o konkretnim delima ili o raznorodnim umetnostima. Moderno razumevanje umetnosti, za razliku od metafizičke tradicije estetike, u tom pogledu ponudilo je nešto izmenjenu sliku u vidu klasičnog sistema umetnosti, unutar kojeg postoji hijerarhijski poredak poznatih umetničkih rodova, te unutra kojeg se pojedine umetnosti - iako priznate kao umetnosti - isključuju iz domena kardinalnih.

Suštinski nov filozofski pristup umetnostima podrazumevao je gest koji o njima ne bi promišljao polazeći od unapred postavljenog zajedničkog pojma i smisla umetnosti, već od njih samih - pre svega od načina na koji se one pojavljuju, od estetskog iskustva. Upravo estetsko iskustvo pokazuje razlike: muzika se najpre recipira čulom sluha, a slikarstvo čulom vida. Međutim, osobenost ovog iskustva,

\footnotetext{
*unapopovic@ff.uns.ac.rs

** Ovaj rad nastao je zahvaljujući podršci Republičkog ministarstva prosvete, nauke i tehnološkog razvoja tokom rada na projektu 179007.
} 
iako očigledna s obzirom na karakter čulnog opažanja koji zahteva, u estetičkom smislu zahtevala je dodatna objašnjenja - takva koja bi precizirala estetske specifičnosti i karakteristike ovih razlika.

Umetnost muzike u ovom pogledu paradigmatski je slučaj. Naime, tradicija filozofskog razumevanja muzike prevashodno je usmerena ka njenim razumski pojmljivim aspektima - ka matematički izrazivim odnosima njenih elemenata, tonova i harmonija. U tom duhu su delali pitagorejci, ali i srednjevekovna podela slobodnih veština muziku tretira kao matematičku nauku, zajedno sa aritmetikom, geometrijom i astronomijom (quadrivium). Osobeno estetičko razmatranje muzike je, stoga, podrazumevalo okret od strogo razumske perspektive razmatranja muzike ka specifično muzičkom estetskom iskustvu. Upravo takav projekat na tragu filozofske misli Imanuela Kanta(Immanuel Kant), u XIX veku sprovodi Edvarad Hanslik (Eduard Hanslick), u svom čuvenom delu $O$ muzički lepom (Hanslik, 1977). Jednom postavljen, Hanslikov formalistički projekat filozofije muzike bitno je odredio njen potonji razvoj, te i danas često predstavlja poziciju spram koje se odmeravaju različite teze o karakteru i smislu muzike.

Hanslikov projekat je, međutim, bio usmeren protiv razumevanja muzike koje bi počivalo na bilo kojim elementima prisutnim u muzici koji nisu izričito muzičkog karaktera. Tako Hanslik o sopstvenom projektu kaže da je on usmeren „protiv općeraširenog shvatanja da muzika ima da 'prikaže osjećaje”" (Hanslik, 1977: 36-37). Slično tome, on tvrdi i sledeće: „ljepota tonskog djela je specifično muzička, tj. imanentna tonskim sklopovima bez odnosa ka nekom stranom, vanmuzičkom misaonom krugu" (Hanslik, 1977: 37-38). Ovi imanentni tonski sklopovi su u Hanslikovom razumevanju zahvaćeni pojmom forme koji, iako je reč o tradicionalnom metafizičkom i estetičkom pojmu, sada treba da igra ulogu posve specifičnu za određenje fenomena muzičkog. Sa Hanslikom, dakle, muzička forma postaje vodeći pojam filozofije muzike. Nasuprot tome, uloga osećanja kao subjektivne reakcije recipijenta dovedena je u pitanje, te se za njeno vraćanje $u$ okvire filozofije muzike uvek iznova očekuje dokaz legitimnosti.

Ovaj rad posvećen je filozofiji muzike Suzan Langer (Susanne Langer) čiji stavovi predstavljaju specifičan odgovor Hansliku, te čije delovanje u kontekstu filozofije umetnosti i muzike bitno određuje potonje rasprave u anglosaksonskoj filozofiji XX veka i danas. Suzan Langer neobična je filozofska figura, budući da njen rad počiva negde između klasičnih pozicija i interesa analitičke filozofije, karakteristične za anglosaksonsku filozofsku misao, i kontinentalne filozofije, uže orijentisane spram tekovina tradicionalne estetike. Za samu Langerovu ovakav prelaz potiče od velikog uticaja koju njena misao duguje filozofiji Ernsta Kasirera 
(Ernst Kasirer). Međutim, Kasirerove pozicije su kod Langerove u velikoj meri posredovane tzv. jezičkim okretom, te preoblikovane iz perspektive primata jezika.

U tom smislu odgovor Langerove na dilemu „osećanja ili forma” zapravo unapred zaobilazi razloge Hasnlikovog dosta redukcionističkog stava. Budući da se navedena dilema više ne razmatra s obzirom na mentalističke, već s obzirom na lingvističke pozicije - s obzirom na primat jezika, a ne svesti - odbacivanje osećanja kao „uljeza” u muzici prestaje da bude pitanje oslobađanja filozofske misli za zahvatanje osobeno muzičkog fenomena. Nasuprot tome, oba pojma - osećanja i forma- biće ispitana upravo kao pojmovi jedne filozofije muzike, adekvatni ili neadekvatni za valjano teorijsko promišljanje muzike. U tom smislu, filozofija muzike Suzan Langer može se posmatrati i kao odlikovani primer promišljanja o uslovima mogućnosti koje jedna filozofija umetnosti, pa i konkretne umetnosti, treba da zadovolji da bi bila prihvatljiva kao dobro vođen teorijski projekat. U redovima koji slede nastojaćemo da ukratko ukažemo na osobenosti ovog poduhvata.

\section{FILOZOFIJA UMETNOSTI U NOVOM KLJUČU}

Osnovna filozofska preokupacija Langerove, čini se, jeste sama filozofija. Reflektujući na mnogobrojne promene i izazove sa kojima se filozofija susrela krajem XIX i početkom XX veka, Langerova Ona filozofiju razume kao odraz transformativne, suštinski preuobličavajuće prirode ljudskog razumevanja (Langer, 1967: 43). „Novi ključ”, tako, predstavlja pojam koji teži da obuhvati ovo permanentno kretanje u oblicima našeg razumevanja stvarnosti; on je više znak novostečene svesti o uvek aktuelnoj prirodi filozofije, nego proklamacija novog programa mišljenja, nove filozofske škole.

Kada je reč o filozofiji, Langerova - u duhu jezičkog okreta - proklamuje da je suštinski transformativna priroda našeg mišljenja ovde vidljiva prevashodno putem njene jezičke artikulacije, odnosno preko konkretnih promena u smislu i funkciji filozofske pojmovnosti. Tako ona tvrdi: ,jedna filozofija [se] pre određuje formulacijom svojih problema negoli rešenjem koje za njih daje" (Langer, 1967: 48-49); kao i da „Formulacija iskustva sadržana u okviru intelektualnog vidokruga jednoga doba ili jednog društva određena je, verujem, ne toliko događajima i željama koliko osnovnim pojmovima kojima ljudi raspolažu da bi, u skladu sa svojim razumevanjem, ispitivali i opisivali svoje doživljaje" (Langer, 1967: 50-51). U svetlu hanslikovske dileme, već na primeru ovog citata možemo primetiti da će fokus Langerove pre biti usmeren na način na koji se pojmovno zahvataju i određuju „doživljaji”, a ne toliko na „događaje” kao sama stanja svesti. 
Centralni pojam filozofije u novom ključu Suzan Langer je, posve u duhu Kasirera, pojam simboličke transformacije. Slično Kasireru, Langerova ovim pojmom želi da naglasi da je suštinska transformativnost našeg mišljenja izraziva u različitim oblicima, odnosno da ona nije rezervisana na domen filozofije - ili verbalne, odnosno teorijske artikulacije uopšte. Upravo na ovom stavu počiva i posledično interesovanje Langerove za umetnost, kao odlikovanu simboličku i transformativnu delatnost čoveka koja izbegava redukciju na racionalnost, pojam i logiku (Budd, 2003: 107-108). Njene studije umetnosti - koje zahvataju i film, i igru, i fotografiju - tako su pre posledica njenog osnovnog filozofskog usmerenja, nego pitanje kojim se ona bavi iz uže estetičkih razloga. Ipak, naglašeni interes za diferenciranje različitih načina simboličkog organizovanja stvarnosti i njihovih transformacija vodi Langerovu i ka izgrađenoj suptilnosti uvažavanja različitih umetnosti kao različitih fenomena, odnosno simboličkih uobličavanja, potirući tako klasičnu ideju jedinstvenog pojma (svih) umetnosti.

O umetnosti, pa i o muzici, Langerova govori već u svom centralnom delu, Filozofiji u novom ključu. Čini se da je izgradnja njenog stava o karakteru i smislu filozofije bar delom vođena iskustvom stečenim u kontaktu sa muzikom. U tom duhu, na primer, Langerova kaže: „Kao što svaka promena tonaliteta daje neki novi smisao prethodnim muzičkim pasažima, tako i preopredeljenje u filozofiji do kojeg dolazi u naše vreme dariva novim vidovima ideje i obrazloženja prošlosti" (Langer, 1967: 41). Langerova celokupno jedno poglavlje svoje knjige posvećuje upravo analizi umetničke simbolizacije, odnosno smisla umetnosti, a naslovljava ga karakteristično - O smislu u muzici. Muzika je, dakle, u okviru projekta Filozofije u novom ključu izdvojena kao odlikovana umetnost, ona čijom se analizom može doći do razumevanja simboličkog uobličavanja smisla karakterističnog za umetnost, za razliku od filozofije, logike i nauke.Ovim, međutim, nije rečeno da je muzika za Langerovu najvažnija ili najvrednija od svih umetnosti. Naprotiv, reč je o tome da je na primeru muzike najlakše izdvojiti onu vrstu simbolizacije koja je načelno karakteristična za umetnost kao sui generis ljudsku delatnost. Muzika je u tom pogledu izdvojena zbog toga što je ona nereprezentativna umetnost, odnosno zbog toga što se umetničko oblikovanje - forma - u slučaju muzike zatiče kao oslobođeno od svih suvišnih primesa. Prema rečima Langeroveu duhu Henslika,,Svoju čistu formu ona [muzika - prim. aut.] ne pokazuje kao neki svoj ukras, već kao samu svoju suštinu” (Langer, 1967: 298), a „Zvuk je sredstvo koje se najlakše koristi na čisto umetnički način” (Langer, 1967: 299).

Ipak, 
„,treba dobro da se čuvamo pogreške prebrzog uopštavanja - pretpostavke da kroz muziku proučavamo sve umetnosti, $\mathrm{i}$ da je svaki uvid u prirodu muzike neposredno primenljiv na slikarstvo, arhitekturu, poeziju, igru i dramu [...] Neko osnovno jedinstvo svrha svih umetnosti - ili, pak, neki opšti metod - jeste vrlo privlačna hipoteza, i na kraju se lako može pokazati da se ona da dokazati; ali kao unapred dat zaključak, kao dogmatska premisa, ta je hipoteza opasna, jer obezoružava posebne teorije i samostalno, tehničko proučavanje” (Langer, 1967, 299).

Karakteristična pozicija muzike u pogledu teorije umetnosti u celini odlikuje i centralno delo S. Langer posvećeno umetnosti - delo karakterističnog naslova, Osećanje $i$ forma. Teorija umetnosti razvijena na osnovu 'Filozofije u novom ključu'. Ovo delo, kako to pokazuje i podnaslov, neposredna je posledica projekta izloženog u studiji Filozofija u novom ključu. Rečima same autorke, ono treba da ispuni obećanje izgradnje jedne kritike umetnosti izvedene po uzoru na već postojeću kritiku nauke, zasnovanu na analizi simbolizma naučnog diskursa (Langer, 1953: VII). Zapravo, Osećanje $i$ forma po svom duhu predstavlja drugi tom Filozofije u novom ključu (Langer, 1953: VII).

Ipak, uprkos očiglednim vezama između dva dela, razlika između njih bitno određuje i način analize muzike; u oba dela, međutim, Langerova polazi od muzike ka drugim umetnostima (Langer, 1953: 27). Naime, pitanje muzike se u slučaju Filozofije u novom ključu postavlja s obzirom na načelni interes projekta realizovanog u ovom delu - projekta potvrđivanja samog ,novog ključa” (Langer, 1967: 41), odnosno razlikovanja između zasebnih načina simboličke transformacije. U slučaju Osećanja i forme reč je o studiji koja se oslanja na već razvijenu teoriju simbolizma, ali i fokusira temu umetnosti, i to sa ciljem da u ovoj oblasti razvije praksu koja je u to vreme uveliko već bila razvijena na nivou filozofije nauke inspirisane delovanjem Bertranda Rasela (Bertrand Russel), Ludviga Vitgenštajna (Ludwig Wittgenstein) i Bečkog kruga - prakse filozofske analize iskaza nauke, te njihovog kritičkog sameravanja sa načelima logike. Ovaj filozofski gest koji vodi od nauke ka filozofiji nauke, od sadržaja naučnih teorija i iskaza ka njihovoj podležećoj logičkoj formi uz pomoć analize jezika i artikulacije nauke kao teorije, postaje sada za Langerovu nit vodilja i za izgradnju adekvatnog filozofskog pristupa umetnosti.

Drugim rečima, Langerova želi da izgradi jednu ,kritiku umetnosti” po uzoru na kritiku nauke - ne u smislu teorijske pozadine umetničke kritike kakvu već poznajemo, već u smislu kritičkog, to jest filozofskog razmatranja umetnosti s obzirom na već postojeće načine njenog razumevanja. Ma kojim interesima da su vođena, ova razumevanja umetnosti su pojmovno artikulisana, te se u tom smislu 
cilja na analizu već postojećih iskaza i stavova o umetnosti - pre nego same umetnosti. Time se, svakako, uvažava razlika između umetnosti same i teorije o njoj, te se zaobilazi tradicionalni gest normativne nadređenosti estetike/teorije umetnosti praksi. Istovremeno, time se posredno postavlja pitanje koji oblik filozofija može adekvatno da preuzme ukoliko treba da svedoči o umetnosti, a da to ne čini a priori, odnosno nametanjem sopstvenih pojmovnih rešenja nepojmovnom simboličkom oblikovanju.

Karakteristika projekta Langerove u kontekstu Osećanja i forme je u tome što kritička i jezička analiza na koju ona misli ne podrazumeva preispitivanje iskaza o umetnosti shodno kriterijumima logike. Naime, formalna logička simbolizacija, posebno razvijena u prvoj polovini XX veka, za Langerovu je samo jedan od oblika simboličkog (i transformativnog) mišljenja. Iako se ona direktno poziva na Vitgenštajnov Traktatus kao na logičku teoriju na kojoj se temelji njeno sopstveno razmatranje o simbolima (Langer, 1967: 139), Langerova ipak smatra da je osnovna pozicija takve logike, „u stavu da je sva artikulisana simbolika diskurzivna” (Langer, 1967: 150), posve pogrešna. Zapravo, Langerova već čulno iskustvo, u duhu Kanta i Kasirera, razume kao proces formulisanja - a samim tim i kao proces (neverbalne) artikulacije, te tvrdi da „oko i uho moraju posedovati svoju logiku svoje 'kategorije razumevanja"' (Langer, 1967: 151). Stoga, kritička analiza umetnosti zahtevala bi gest koji bi, slično jezičko-logičkoj analizi, pokazao osnovne forme vezane za umetnost, njihove odnose i transformacije, ali su takve forme shvaćene kao simboličke u smislu koji prevazilazi čistu racionalnost i diskurzivnost logike.

Osećanja i forma je, tako, delo posvećeno filozofskoj analizi pojmova, odnosno značenja reči poput ekspresije, kreacije ili simbola, reči na osnovu kojih se organizuje razumevanje umetnosti, a posebno veza između umetnosti i osećanja (Langer, 1953: VIII). Prema rečima Langerove, „Osnovni cilj ove knjige se, stoga, može predstaviti kao konstrukcija intelektualnog okvira za filozofska istraživanja $u$ vezi sa umetnošću, bila ona načelna ili konkretna" [prev. aut.] (Langer, 1953: IX). U narednom poglavlju predstavićemo mesto muzike u ovim okvirima.

\section{MUZIKA I OSEĆANJA: OSNOVNI PROBLEMI FILOZOFIJE MUZIKE}

Svoje istraživanje teorije umetnosti Langerova započinje jednom za nas značajnom konstatacijom - naime, tezom da problemi filozofije umetnosti počivaju na pretenziji filozofa da barataju sa tzv. opštim pojmovima, koja rezultuje sasvim načelnim perspektivama kojima se oni u svojim istraživanjima vode (Langer, 1953: 4-5). Nasuprot tome, Langerova predlaže sistemsko promišljanje i preformulisanje, 
„posebnu formulaciju skoro svakog važnog problema u vezi sa umetnošću” [prev. aut.] (Langer, 1953: 10). Prema njenom sudu, ispravna formulacija može pokazati da se pojedine teorije o umetnosti, za koje smatramo da se međusobno isključuju, zapravo mogu usaglasiti (Langer, 1953: 16).

Upravo takav nov pogled Langerova daje i u pogledu na tradicionalnu Hanslikovu dilemu u filozofiji muzike - osećanje ili forma? Najpre, Langerova tvrdi da su forme muzike logički slične formama ljudskih osećanja: „muzika je tonalni analogon emotivnog života", tvrdi ona [prev. aut.] (Langer, 1953: 27). Na prvi pogled, ovaj stav kao da stoji u suprotnosti sa Hanslikovom pozicijom - ali i sa prethodno citiranim stavovima same Langerove iz Filozofije u novom ključu, u kojima autonomiju muzike vidi u duhu muzičkih formi a la Hanslik. Ipak, prividna protivrečnost razrešava se sledećim tumačenjem: „Ako muzika ima ikakvog smisla, taj smisao je semantičke, a ne simptomske prirode. Očigledno je da 'značenje' muzike nije značenje nadražaja koji izaziva emocije, niti značenje signala koji ih najavljuje; ako poseduje neku emocionalnu sadržinu, muzika je 'ima' u onom istom smislu u kojem jezik 'ima' svoju pojmovnu sadržinu - to jest, sadrži je simbolički. [...] Muzika nije uzrok osećanja niti lek za njih, već njihov logički izraz" (Langer, 1967: 309-310).

Kako vidimo, uprkos čvrstoj vezi muzike i osećanja, Langerova ipak jasno pokazuje da muzika, čak ni u pogledu svog sadržaja - svog smisla, nije emotivnog karaktera. Naprotiv, ona ima sebi svojstven smisao, rezervisan za njoj autentični tonalni domen, slično Hansliku. Ovaj smisao muzike označen je kao semantički i simbolički: on je simbolički u meri u kojoj za Langerovu bilo koje pojavljivanje smisla podrazumeva oblikotvornu simboličku delatnost čoveka, ovde neverbalne i osobeno muzičke vrste. Sa druge strane, uvođenjem odrednice „semantičko" Langerova ukazuje na mogućnost primene uvida stečenih u okvirima istraživanja jezika na analizu muzike: muzika tako ima sebi svojstvenu formu - ali i sebi svojstven muzički „sadržaj”, na koji se cilja kada se govori o semantici (Hausman, 1989: 13-14). Osobenost ovog muzičkog sadržaja, u odnosu na jezički, jeste u tome da on nema fiksiran semantički smisao (Budd, 2003: 108).

Veza između muzike i osećanja, međutim, predstavljena je kao logička i analoška veza istovremeno (što i samo deluje kao paradoks) (Addis, 2004: 24). Pod analogijom Langerova misli na tzv. formalnu analogiju - na uklapanje logičkih struktura, za koju takođe tvrdi i to da je ona nužna da bi se ostvarila relacija između simbola i njegovog značenja (Langer, 1953: 27). Drugim rečima, kada govori o logici, Langerova ne misli na matematičku logiku i njena pravila, već na logos, oblik samih simbola i njihove organizacije, odnosno na uklapanje forme simbola i 
simbolizovanog objekta. Imajući to $\mathrm{u}$ vidu, sada možemo razjasniti smisao prethodno citiranog određenja muzike: Langerova, dakle, ne tvrdi da se muzika sastoji od osećanja ili da ih izražava - kako se često misli, već ukazivanje na analogiju služi kao objašnjenje razloga usled kojih se muzika teorijski dovodi u vezu sa osećanjima, kao i potvrđenih slučajeva uticaja muzike na osećanja.

Međutim, ovo objašnjenje je istovremeno, izvedeno pozivanjem na formu muzike - odnosno, pozivanjem na formalnu relaciju između osećanja i muzike, koja je dodatno precizirana kao logička. Kako treba razumeti ovu formalnost? Već na prvi pogled očigledno je da formalnost $u$ ovom slučaju ne može biti mišljena $u$ Hanslikovom duhu, budući da se muzika, čak i da se zadržimo na njenoj čisto muzičkoj, estetskoj formi, ipak neposredno povezuje sa osećanjima. Formalna relacija između osećanja i muzike ne znači da muzika referira na osećanja, niti da je forma muzike identična sa nekom pretpostavljenom formom osećanja. Podjednako, prema mišljenju Langerove, muzika uopšte nema referencijalni karakter (Addis, 2004: 26-27), te utoliko ne može biti izjednačena sa jezikom i semantikom u uobičajenom smislu reči.

Vezu između muzike i osećanja treba razumeti kao strukturnu vezu (Kühl, 2008: 117). Pozicija jezika koju Langerova zauzima omogućava da njen karakter bude preciznije određen: muzika se sastoji od tonalnih elemenata koji se uklapaju u različite tonalne strukture - oni svojim međusobnim odnosima upravo određuju smisao muzičkog, jer izbacivanje ili ubacivanje bilo kog elementa menja kvalitet muzike. Ove strukture su, stoga, slične jezičkim jer podrazumevaju kontekstualnu uslovljenost - ali ne i referencijalnost (Innis, 2009: 84). Izostajanje referencijalnosti podrazumeva formalnu vezu: muzička forma kao simbol osećanja podrazumeva osoben način njihovog zahvatanja, način na koji se ona pojavljuju za svest preko nečeg drugog (svog simbola), a ovo podrazumeva da simbol mora biti slične strukture kao i ono što on simbolizira (Budd, 2003: 106). Muzika i osećanja, dakle, nisu isto, ali su u pogledu svojih strukturnih oblika dovoljno slični da bi jedno moglo postati simbol drugog; u ovom pogledu jasno se vidi uticaj Vitgenštajna.

Sa druge strane, muzičko simboličko uobličavanje odstupa od jezika i u pogledu toga kakav smisao može da izrazi. Naime, iako nema referencijalni karakter, muzika upravo zbog toga može da izrazi ono što jezik ne može; utoliko je ona mnogo bolji izraz osećanja nego što to može biti njihovo imenovanje (Innis, 2009: 84). Muzika je neiscrpna u svom smislu, baš zbog toga što njen smisao nije i ne može biti fiksiran za bilo kakav referent. Shodno tome, muzika je kompatibilnija sa oblicima ljudske osećajnosti nego što je to jezik. Sa druge strane, to podrazumeva da muzička forma nije apstraktna, već sadržajno-simbolička: 
umetničke forme su po Langerovoj logički ekspresivne, odnosno značenjske forme (significant form, pojam koji je preuzet od Klajva Bela (Clive Bell)) (Langer, 1953: $52)$.

Logička ekspresivnost je, očigledno, vrlo neobičan pojam. Čini se da Langerova ovde pokušava da istovremeno bude i za i protiv Hanslika, odnosno da ona pokušava da zadrži vezu između muzike i osećanja, a da je ne interpretira tako da muzika predstavlja puki izraz emocija. Umesto toga, muzika je njihov logički izraz, što pre svega upućuje na otklon od teze da osećanja predstavljaju muzički sadržaj. Istovremeno, u pitanju je i otklon od teze da je muzička forma identična sa formom ljudskih osećanja, odnosno da se na nju može redukovati.

Drugim rečima, Langerova tvrdi da muzika nije isto što i osećanja, ni spram svog sadržaja, ni spram svoje forme. Suštinska veza izemđu muzike i osećanja, koju Langerova uprkos tome želi da održi, interpretirana je neutralnije i donekle neprecizno, povlačenjem korak unazad ka formalnom odnosu struktura dva naglašena domena. Njihova formalnost, međutim, ne može biti jasno i strogo opisana ovde jer bi takav opis podrazumevao bilo jezičke, bilo uže logičke alatke analize, koje bi nesumnjivo isključile upravo ono što je po Langerovoj osobeno i svojstveno kako muzici, tako i osećanjima.

Opravdanje za ovako neobičan postupak Langerove možemo tražiti tek u načelnim njenim stavovima o filozofiji u novom ključu, koje smo iz tih razloga prethodno i navodili. Naime, reč je o načelnom pristanku na mogućnost smisla koji ne bi mogao biti verbalno ili racionalno artikulisan, već čija artikulacija i formacija podrazumeva posve drugačije forme i strukture od jezičkih (Innis, 2009: 89). Ukoliko prisvojimo ovakvu poziciju, onda neodređeni odnos muzičkih i emotivnih struktura, kao i veoma problematični stav da i emotivna strana čoveka ima sebi svojstvene forme (Richter, 2007: 112), možemo razumeti pre kao otvaranje novog horizonta filozofskog istraživanja nego kao neuspeh u ispunjavanju tradicionalnih zahteva filozofije; napokon, ovo je filozofija u novom ključu.

$\mathrm{U}$ tom smislu, smatramo, treba kritički sagledati one interpretacije Langerove koje, donekle površno, tvrde da je u pitanju izjednačavanje muzike i osećanja. Čini se da one proističu upravo iz zanemarivanja naglašenog poziva Langerove na novu filozofiju, nove perspektive razumevanja organizacije smisla datim čoveku. U tom kontekstu, gledano iz perspektive tradicije, jedino plauzibilno rešenje nejasnih stavova Langerove jeste interpretacija prema kojoj ona izjednačava muziku i osećanja. Ipak, u svetlu prethodno rečenog, stava smo da je ovo isuviše pojednostavljeno: ma koliko njeni stavovi možda nisu dovoljno precizirani, 
smatramo da to ne daje tumačenju za pravo da zanemari ograde koje je sama autorka povukla.

Filozofska analiza muzike, tako, prema Langerovoj mora da vodi računa o tri međusobno nesvodiva i različita poligona: o muzici, o osećanjima, te o domenu jezika, pojma i logike, koji je njoj samoj svojstven. Imajući u vidu da je predmet takvog istraživanja - muzika, u svojoj suštinskoj vezi sa osećanjima - načelno neizraziv formama i strukturama jezičke artikulacije, jedna filozofija muzike morala bi naročito da vodi računa o sopstvenom postupku i odabiru pojmovnosti prikladne takvom zadatku.

\section{ZAKLJUČNA RAZMATRANJA}

Iako propagira simbolističku ideju muzike, Langerovoj se često prigovara da nije dovoljno precizno objasnila naglašenu vezu između muzike i osećanja; jednako često joj se zamera i što pitanje ontološkog statusa muzike nije predmet njenih interesovanja (Addis, 2004: 31-32). Ukoliko se oslonimo na prethodne analize, ovim primedbama možemo uputiti i adekvatne odgovore.

Kada je reč o nedovoljno preciznoj razjašnjenosti veze između muzike i osećanja, čini se da je navedeni prigovor Langerovoj upućen bez uvažavanja njenih sopstvenih pozicija. Kako smo videli, Langerova ne pristaje na diskurzivnost i njoj svojstvenu logiku kao jedini mogući okvir uspostavljanja smisla; usvajanjem neverbalnih simbola kao nosilaca smisla i mogućeg razumevanja stvarnosti ona isključuje zahteve ove vrste. Reč je upravo o tome da se jedan simbolički poredak ne nameće drugom, odnosno da se dopusti mnogostrukost takvih poredaka. Ukoliko se, kao u slučaju muzike i posledično njene veze sa osećanjima, radi o neverbalnom simboličkom poretku, njegov sadržaj se per definitionem ne može verbalno artikulisati; otuda je prigovor Langerovoj neprimeren.

Međutim, filozofska analiza ne zadržava se na nivou semantike, sadržaja ona jednako može biti i formalna, te Langerova upravo to i nudi. Njena filozofija muzike polaže računa samo o onome što je filozofskim sredstvima u ovom pogledu moguće izraziti, a to su formalni odnosi koji se mogu opisati i analizirati s obzirom na neverbalni simbol (muziku) koji razmatramo. U tom smislu filozofija muzike nije pretenciozna: ona ne prekoračuje granice svog filozofskog karaktera. Ona će razmatrati samo ono što je $u$ pogledu muzike dostupno diskurzivnoj misli, a to je sam njen simbolički karakter. Time je objašnjeno i izostajanje interesa za ontološki status muzike.

Ipak, upravo ovako postavljena filozofija muzike Langerove može da pretenduje na povezivanje forme i osećanja, razmatrajući ih s obzirom na okvire 
koje otvara jezički okret, odnosno kao pojmove koji su u tradiciji odlikovano vezani za teorijsko razmatranje muzike. Pojam osećanja se, tako, sada uzima kao oznaka onoga na šta muzika kao simbolički oblik upućuje, bez da se sa njim može identifikovati. Sa druge strane, pojam forme nužan je aspekt tako zamišljenog simboličkog odnosa, jer on u minimalnom smislu označava samu simboličku vezu, na taj način upravo odražavajući razliku između muzike kao simbola i osećanja kao onog simbolizovanog. Muzika je, tako, za Langerovu simbol - a forma i osećanja su načini teorijskog opkoljavanja njenog neizrecivog smisla.

Una Popović

\section{PHILOSOPHY OF MUSIC BETWEEN FEELING AND FORM Susanne Langer on music in a new key}

\section{Summary}

This paper addresses Susanne Langer's philosophical analysis of music. Langer's approach to music will be examined in view of two main traditional alternatives for defining the essence of music - namely, form and feelings. The dilemma of music between feelings and form was posed by E. Hanslick, and Langer is redefining its meaning and purpose by accepting the linguistic turn and transforming the very idea of philosophy of music. For Langer, music is a non-verbal symbol, allowing us to comprehend our feelings; however, there is no identity between music and feelings. Such position of Langer is to be understood as a consequence of the mentioned transformation of the idea of the philosophy of music. Through questioning of form and feeling as possible candidates for the essence of music, Langer suggests that they are to be considered and analyzed not as things themselves, but as concepts used in developing theoretical approaches to music. The resulting philosophy of music in Langer transcends Hanslick's dilemma.

Key words: Susanne Langer, music, philosophy of music, form, feelings.

\section{LITERATURA}

Addis, L. (2004). Of Mind and Music. Ithaca: Cornel University Press.

Budd, M. (2003). Music and Emotions: The Philosophical Theories. London: Routledge.

Hanslik, E. (1977). O muzički lijepom. Beograd: BIGZ.

Hausman, C. R. (1989). Metaphor and Art: Interactionism and Reference in the Verbal and Nonverbal Arts. Cambridge: Cambridge University Press.

Innis, R. E. (2009). Susanne Langer in Focus: The Symbolic Mind. Bloomington: Indiana University Press. 
Langer, S. (1953). A Theory of Art Developed from Philosophy in a New Key. New York: Charles Schribner's Sons.

Langer, S. (1967). Filozofija u novome ključu. Beograd: Prosveta.

Richter, C. (2007). The body of Susanne K. Langer's Mind. In: Krois, J. M.Rosengren, M.-Steidele, A. \& Westerkamp, D. (eds.) (2007). Embodiment in Cognition and Culture. Amsterdam: John Benjamins Publishing. 